\title{
Semiannual Cycle in Zonal Wind over the Equatorial Indian Ocean
}

\author{
TOMOMIchi Ogata AND SHAng-PING XIE \\ International Pacific Research Center, University of Hawaii at Manoa, Honolulu, Hawaii
}

(Manuscript received 14 December 2010, in final form 4 June 2011)

\begin{abstract}
The semiannual cycle in zonal wind over the equatorial Indian Ocean is investigated by use of oceanatmospheric reanalyses, and linear ocean-atmospheric models. In observations, the semiannual cycle in zonal wind is dominant on the equator and confined in the planetary boundary layer (PBL). Results from a momentum budget analysis show that momentum advection generated by the cross-equatorial monsoon circulation is important for the semiannual zonal-wind cycle in the equatorial Indian Ocean. In experiments with a linearized primitive model of the atmosphere, semiannual momentum forcing due to the meridional advection over the central equatorial Indian Ocean is important to simulate the observed maxima of the semiannual cycle in equatorial zonal wind. Off Somalia, diabatic heating and surface friction over land weaken the semiannual response to large momentum forcing there. Results from a linear ocean model suggest that the semiannual zonal wind stress over the central equatorial Indian Ocean generates large semiannual variability in zonal current through a basin-mode resonance.
\end{abstract}

\section{Introduction}

The tropical Indian Ocean features a strong seasonal cycle associated with monsoon. Convective heating due to Indian monsoon rainfall south of the Himalayas generates southwesterly (southeasterly) winds in the northern (southern) tropical Indian Ocean during boreal summer. In contrast, the Austral summer monsoon and southward displacement of the intertropical convergence zone (ITCZ) to $10^{\circ} \mathrm{S}$ generates northeasterlies (northwesterlies) in the Northern (Southern) Hemisphere during boreal winter. Tropical Indian Ocean climate features variability on various time scales (Schott et al. 2009). On interannual time scales, the Indian Ocean dipole mode, in which sea surface temperature (SST) is cooler (warmer) than the seasonal climatology in the eastern (western) equatorial Indian Ocean, is an important phenomenon (Saji et al. 1999; Webster et al. 1999). It is recognized as the second EOF mode for SST and first mode for the thermocline depth (Behera et al. 2003, 2006; Saji et al. 2006). IOD events affect the global climate through atmospheric teleconnection patterns (Saji and Yamagata 2003). The

Corresponding author address: Tomomichi Ogata, Pacific Ocean Science and Technology Bldg., Room 401, 1680 East-West Road, International Pacific Research Center, University of Hawaii at Manoa, Hawaii, HI 96822.

E-mail: ogatat@hawaii.edu
Madden-Julian oscillation is dominant on intraseasonal time scales, originating from the tropical Indian Ocean where SST exceeds $28^{\circ} \mathrm{C}$ (Hendon and Salby, 1994; Zhang 2005). Both interannual and intraseasonal variability is seasonally phase locked (e.g. Madden 1986; Zhang 2005; Saji et al. 1999, 2006).

The equatorial Indian Ocean features a pronounced semiannual cycle, especially in zonal wind (e.g. Schott and McCreary 2001). In boreal spring and fall (summer and winter), westerly (easterly) winds prevail on the equator. The oceanic response to such semiannual wind variability has been investigated extensively from observations (Knox 1976; Luyten and Roemmich 1982; McPhaden 1982; Reppin et al. 1999; Nagura and McPhaden 2008) and with model experiments (Gent et al. 1983; Clarke and Liu 1993; Yuan and Han 2006). A strong eastward current during the westerly wind phase is known as the "Yoshida-Wyrtki jet" (Yoshida 1959; Wyrtki 1973), affecting the seasonal variability of the Indonesian Throughflow through the coastal Kelvin wave propagation along Sumatra and Java coasts (Yamagata et al. 1996; Qu et al. 2008). Furthermore, the easterly wind during boreal summer shoals the thermocline in the eastern equatorial Indian Ocean, which forms favorable conditions for IOD events through the Bjerknes feedback.

Han et al. (1999) investigated the dynamics of the semiannual zonal current variability in the equatorial 
Indian Ocean by using a 4.5-layer ocean model. They proposed that the semiannual cycle in zonal current can be explained by a basin-scale resonance of the Kelvin and Rossby waves, especially for the second baroclinic mode (Jensen 1993). This resonance mechanism is based on a linear theory with the semiannual surface wind as an external forcing. However, the mechanism for the semiannual wind cycle itself in the equatorial Indian Ocean has never been investigated in the literature.

As a possible cause of the semiannual zonal wind variability in the equatorial Indian Ocean, we propose meridional momentum advection due to the asymmetric monsoonal wind on the equator. Okumura and Xie (2004) studied the seasonal cycle in zonal wind over the equatorial Atlantic Ocean and showed that significant momentum advection due to northward displacement of the ITCZ contributes to the annual intensification of easterly wind on the equator during boreal spring to summer. Likewise in the equatorial Indian Ocean, meridional wind shear $(\partial u / \partial y)$ and crossequatorial wind $(v)$ associated with monsoons can be a significant momentum source through the momentum advection $(-v \times \partial u / \partial y)$.

The present study investigates the origin of the pronounced semiannual cycle in zonal wind over the equatorial Indian Ocean by using atmospheric reanalysis datasets and a linearized primitive model forced by thermal and momentum forcing. Especially, we would like to address the following two questions: what is the mechanism for the semiannual zonal wind variability in the equatorial Indian Ocean, and specifically, how much does the momentum advection effect contribute to the semiannual cycle?

The specific hypothesis we wish to test is that the momentum advection due to the interhemispheric monsoon circulation drives the semiannual cycle of surface zonal wind in the equatorial Indian Ocean. Consider a simple, meridionally one-dimensional case, for which the zonal momentum equation may be cast as

$$
\left(\bar{v} \frac{\partial u}{\partial y}+v \frac{\partial \bar{u}}{\partial y}\right)+v \frac{\partial u}{\partial y}-f v=-\varepsilon u,
$$

where $(u, v)$ are seasonal deviations of the planetary boundary layer (PBL) wind velocity from the annual mean denoted with the overbar, $f$ is the Coriolis parameter, and $\varepsilon$ is the linear drag coefficient. Over the equatorial Indian Ocean, $(\bar{u}, \bar{v})$ are weak and will be set zero for simplicity here. For small $(u, v)$, the linear terms dominate to first order, at which Eq. (1) becomes

$$
-f v_{0}=-\varepsilon u_{0}
$$

On the equator, $u_{0}=0$. The next-order momentum equation is

$$
\frac{\beta}{\varepsilon} v_{0}^{2}+\frac{f}{\varepsilon} v_{0} \frac{\partial v_{0}}{\partial y}-f v_{1}=-\varepsilon u_{1}
$$

Assuming $f=0$ on the equator, from (3) one obtains

$$
u=u_{1}=-\frac{\beta}{\varepsilon^{2}} v_{0}^{2} .
$$

Over the Indian Ocean, while $v_{0}$ is dominated by an annual cycle associated with the interhemispheric monsoons, Eq. (4) indicates that zonal wind on the equator responds with a semiannual cycle because the easterly acceleration by the cross-equatorial advection peaks twice a year, respectively, in winter and summer. This semiannual cycle is pronounced on the equator because the vanishing Coriolis force cannot balance the momentum advection. The real Indian Ocean is bounded by land on the east and west sides, and zonal variations are important. Zonal pressure gradient plays a role, as part of the dynamical adjustment to cross-equatorial momentum advection as will be studied in detail in this paper.

Section 2 describes reanalysis datasets used in this study. Section 3 describes the semiannual wind cycle based on observations, presents a momentum budget analysis, and shows the importance of the momentum advection term for the semiannual cycle in zonal surface wind. Section 4 examines dynamical mechanisms using simulated results and investigates the relative contribution of the thermal and momentum forcing. Furthermore, the contribution of equatorial waves, especially the effects of the Rossby wave, Kelvin wave, and reflected equatorial Kelvin wave at the western boundary and their dependence on surface friction are considered in terms of the analytic solution. Section 5 describes the oceanic response to the semiannual wind. Section 6 is a summary.

\section{Data}

We use the Japanese 25-yr reanalysis (JRA-25; Onogi et al. 2007) and Japan Metrological Agency (JMA) Climate Data Assimilation System (JCDAS) products from the JMA. The latter uses an assimilation system similar to JRA-25 reanalysis. Model resolution used in the assimilation is T106L40, and the three-dimensional variational data assimilation (3D-Var) method is used. Wind profile retrievals from tropical cyclone soundings (Fiorino 2002) are assimilated, which improves wind profiles in the tropics. JRA-25 covers January 1979 to December 2004 and JCDAS (the real-time reanalysis) from January 2005 to present. The original datasets are 
(a)

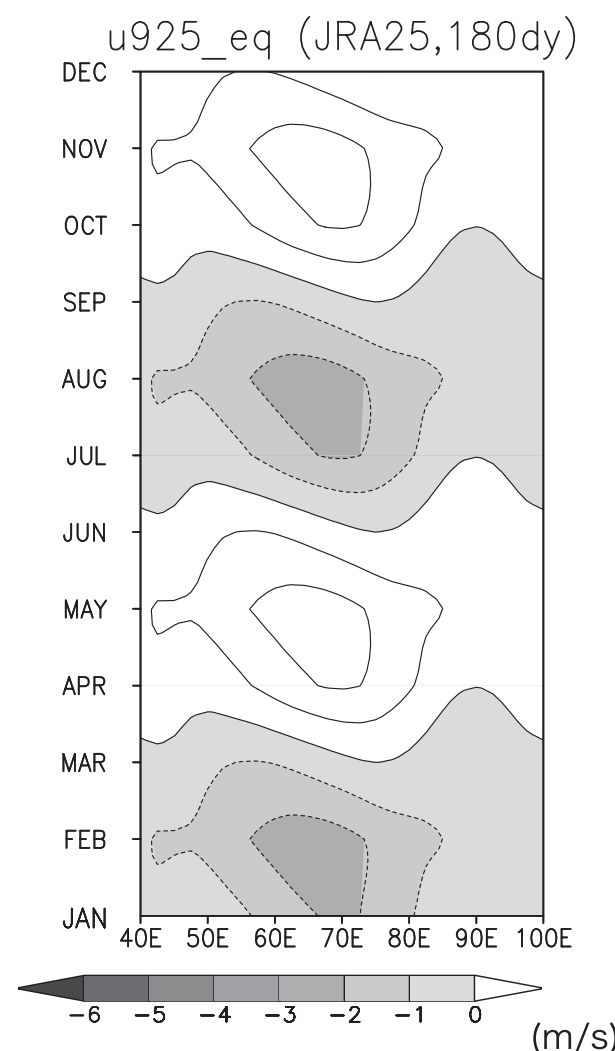

(b)

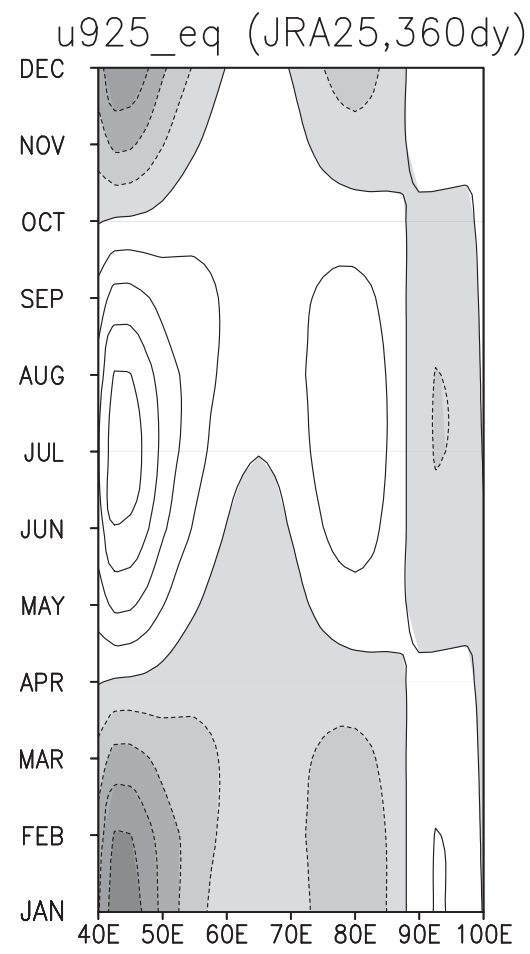

FIG. 1. Longitude-time sections of climatological zonal wind $\left(\mathrm{m} \mathrm{s}^{-1}\right)$ variability on the equator for (a) the semiannual and (b) the annual harmonics at $925 \mathrm{hPa}$. Negative values are shaded.

provided at six-hourly intervals. This study uses a grid spacing of $2.5^{\circ}$ in the horizontal and 23 levels in the vertical. Monthly mean values from six-hourly datasets are constructed, and its monthly climatology from January 1979 to December 2008 will be used in this study.

\section{Observations}

Figure 1 exhibits the monthly climatology of zonal wind on the equator at $925 \mathrm{hPa}$ as a function of longitude and time. Consistent with previous studies (Clarke and Liu 1993; Han et al. 1999; Schott and McCreary 2001), the semiannual cycle is dominant in the central Indian Ocean from $60^{\circ}$ to $90^{\circ} \mathrm{E}$, with its phase propagating slightly westward (Fig. 1a). By contrast, the annual cycle is dominant in the western Indian Ocean, manifested as alternations between the strong southwesterly Somali Jet during boreal summer and the northeasterly wind that converges onto the ITCZ at $10^{\circ} \mathrm{S}$ during boreal winter (Fig. 1b) (e.g., Schott and McCreary 2001).

Figure 2 shows horizontal distribution of annual and semiannual harmonics for zonal wind at $925 \mathrm{hPa}$. There are clear differences between two harmonic components.
First, the annual zonal wind cycle is strong off the equator, over the Arabian Sea and Bay of Bengal in the Northern Hemisphere and around $10^{\circ} \mathrm{S}$ in the Southern Hemisphere (Fig. 2a). On the other hand, the semiannual component has a significant maximum in the central equatorial Indian Ocean from $50^{\circ}$ to $80^{\circ} \mathrm{E}$, a structure distinct from the annual component (Fig. 2b). Significant semiannual signals also appear in other regions: in the northern tropical Indian Ocean and southwestern Indian Ocean around $10^{\circ} \mathrm{S}$, where annual signals are larger. Thus the semiannual zonal wind cycle in the equatorial Indian Ocean is a significant and robust phenomenon (Gent et al. 1983).

The semiannual variability in wind is trapped within the PBL. Figure 3 shows the longitude-height section of the semiannual zonal wind harmonic on the equator. The semiannual component is significant in the upper troposphere and the PBL below $800 \mathrm{hPa}$. In the PBL, the maximum is located around $925 \mathrm{hPa}$ with a decrease toward the surface. Our focus is the formation mechanism for the semiannual zonal wind variability at the surface, so the origin of the semiannual signal near the tropopause is beyond our scope. 

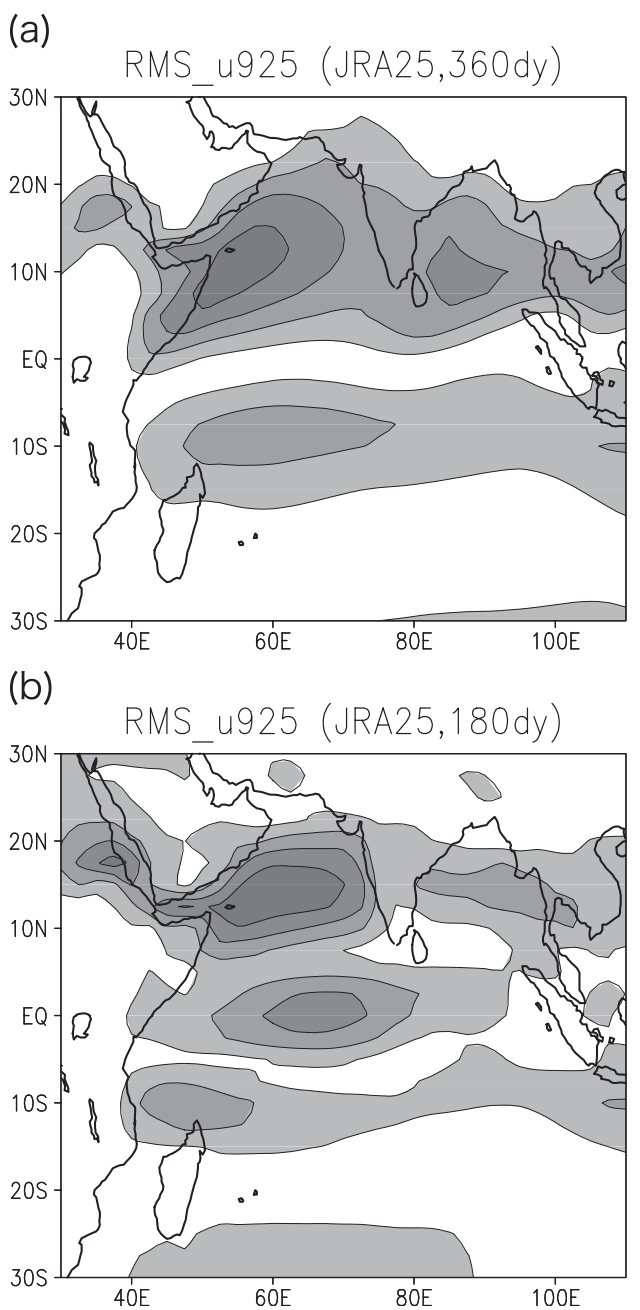

FIG. 2. Horizontal distribution of (a) the annual and (b) the semiannual harmonics for the zonal wind $\left(\mathrm{m} \mathrm{s}^{-1}\right)$ at $925 \mathrm{hPa}$.

\section{Momentum budget on the equator}

As stated in the introduction, our hypothesis is that momentum advection due to the cross-equatorial monsoon circulation plays a key role in semiannual zonal wind variability over the equatorial Indian Ocean. Figure 4 shows the seasonal variability of surface wind and the momentum advection $\left(-v^{*} \times \partial u / \partial y\right)$ on the equator. In the Indian Ocean (Fig. 4a), the meridional wind has an annual cycle, southerly (northerly) during boreal summer (winter). On the other hand, a semiannual cycle is dominant for the momentum advection, which peaks twice per year during January and July-August. These results support the hypothesis.

To test this hypothesis further, we compare a momentum budget on the equator. The zonal momentum equation on the equator within the PBL, which is generally below $850 \mathrm{hpa}$, can be expressed as follows:

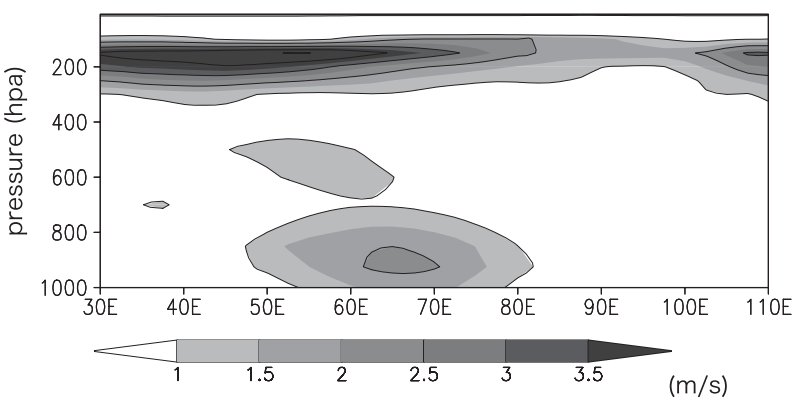

FIG. 3. Longitude-height distribution of the semiannual harmonic for the zonal wind $\left(\mathrm{m} \mathrm{s}^{-1}\right)$ on the equator. The contour interval is $1 \mathrm{~m} \mathrm{~s}^{-1}$.

$$
\varepsilon u=-\frac{\partial \Phi}{\partial x}-u \frac{\partial u}{\partial x}-v \frac{\partial u}{\partial y}+\text { res. }
$$

where the left-hand side indicates the friction, the first term on the right-hand side is the pressure gradient, the second and third terms are the zonal and meridional momentum advection, and the last term is the residual. The momentum budget is calculated at $925 \mathrm{hpa}$ where the semiannual wind cycle is the maximum (see Fig. 3).

Figure 5 compares the semiannual cycle in pressure gradient and advection at $925 \mathrm{hPa}$ in Eq. (5) on the equator. The pressure gradient term is large from $40^{\circ}$ to $60^{\circ} \mathrm{E}$ and generates westerly (easterly) acceleration during boreal winter and summer (spring and fall) (Fig. 5a). There is a semiannual cycle in surface heating over Africa; continental warming (cooling) in boreal spring and fall (winter and summer) induces easterly (westerly) winds over the equatorial Indian Ocean. Furthermore, semiannual SST cooling in the western Indian Ocean during boreal winter and summer can also generate westerly winds (Murtugudde and Busalacchi 1999). The horizontal advection term is large in the western equatorial Indian Ocean and is out of phase with the pressure gradient term (Fig. 5b). The maximum momentum advection off Africa is due to the seasonal-alternating Somali jet. The cross-equatorial circulation generates the large momentum advection $\left(-v^{*} \times \partial u / \partial y\right)$ with easterly acceleration in both boreal summer and winter seasons. The out-of-phase relationship between the pressure gradient and the momentum advection reduces their sum in the western basin (Fig. 5c). The sum of these two effects displays a westward phase propagation (Fig. 5c), consistent with the propagation of the semiannual harmonic in zonal wind (Fig. 1a). There is a secondary peak in the momentum advection in the central Indian Ocean from $80^{\circ}$ to $90^{\circ} \mathrm{E}$, and it is nearly in-phase with the pressure gradient in the central Indian Ocean. The sum of the pressure gradient and momentum advection is, however, comparable between the western and central basins. 
(a)

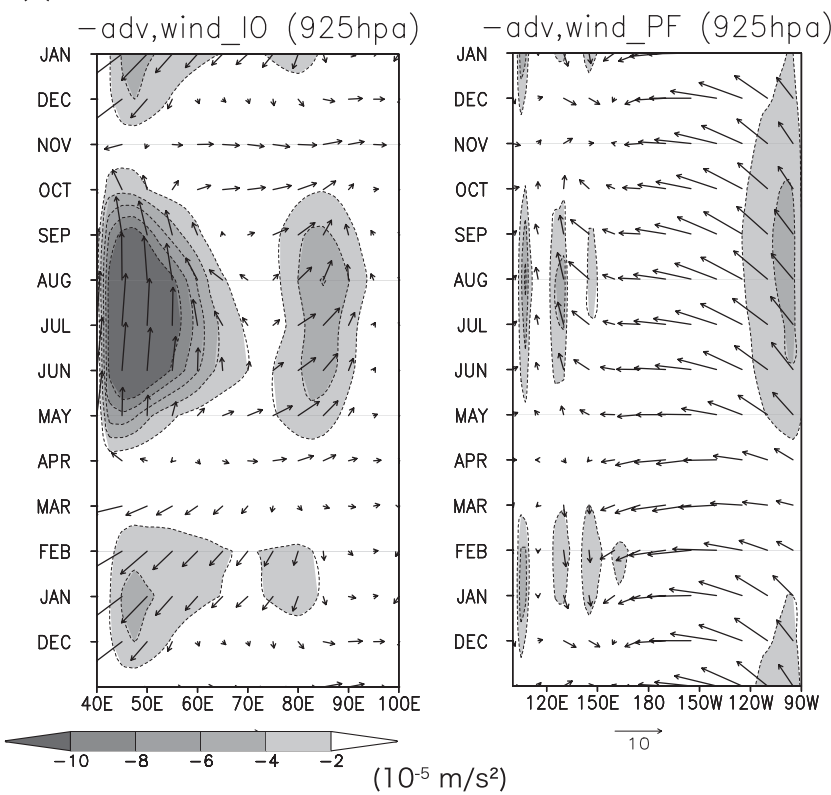

(c)

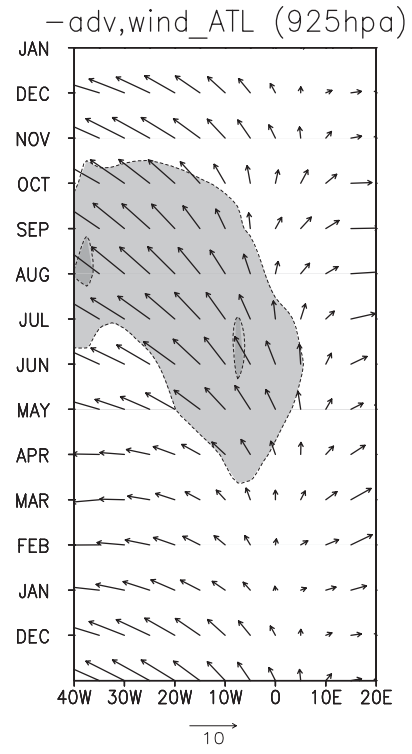

FIG. 4. Longitude-time sections of the monthly climatology for the cross-equatorial momentum advection $\left(-v^{*} \times \partial u / \partial y\right.$, shaded) and horizontal wind velocity (vectors in $\mathrm{m} \mathrm{s}^{-1}$ ) at $925 \mathrm{hPa}$ on the equator: (a) the Indian Ocean, (b) Pacific, and (c) Atlantic. The shading intervals are $2 \times 10^{-5} \mathrm{~m} \mathrm{~s}^{-2}$.

In the western basin, pressure gradient opposes advection, a relationship that turns out not to be coincidental but results from atmospheric adjustment near African highlands.
Figure 6 exhibits the longitude-height distribution of the semiannual harmonic of the momentum advection term in Eq. (5). Similar to the semiannual zonal wind cycle itself (Fig. 3), the semiannual momentum advection (a)

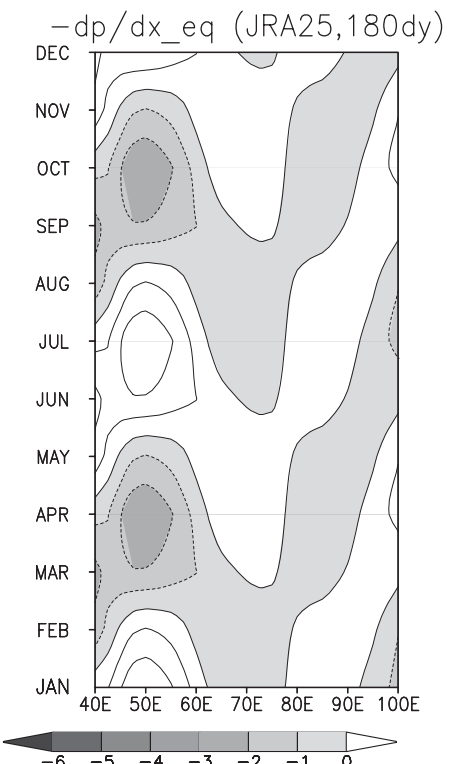

(b)

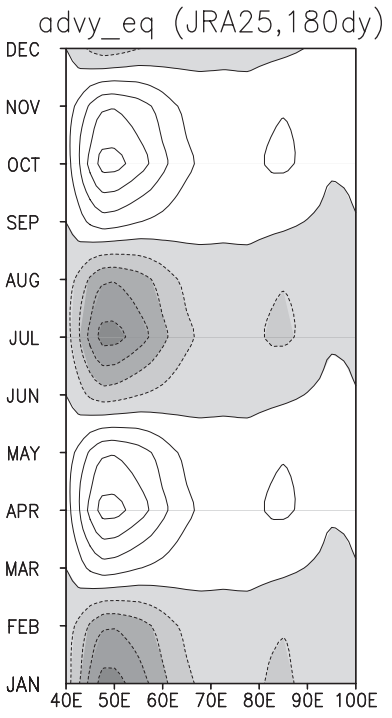

(c)

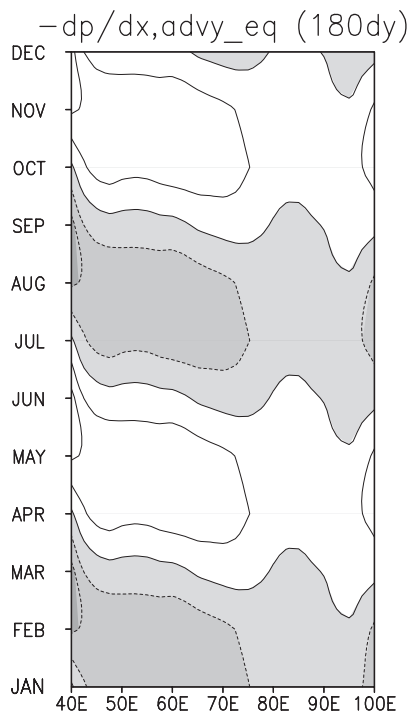

$\left.10^{-5} \mathrm{~m} / \mathrm{s}^{2}\right)$

FIG. 5. Longitude-time sections of terms in Eq. (5): (a) the zonal pressure gradient, (b) the momentum advection, and (c) their sum for the semiannual component at $925 \mathrm{hPa}$. The contour and shading intervals are $10^{-5} \mathrm{~m} \mathrm{~s}^{-2}$. Negative values are shaded. 


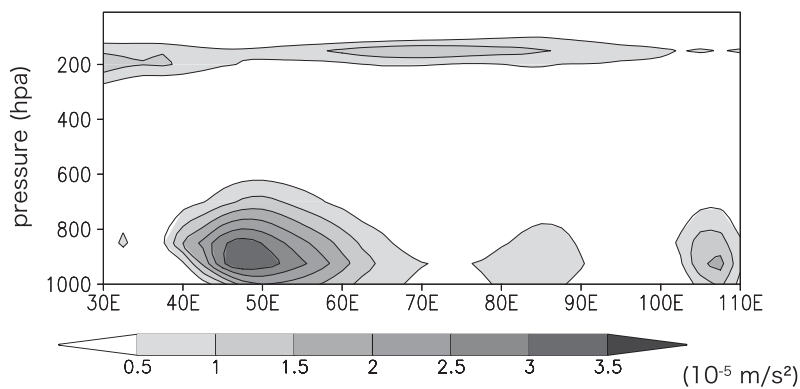

FIG. 6. Longitude-height distribution of the semiannual harmonic for the momentum advection $\left(10^{-5} \mathrm{~m} \mathrm{~s}^{-2}\right)$ on the equator.

is confined below $850 \mathrm{hPa}$, suggesting its importance for the semiannual zonal wind cycle. A major peak is in the western Indian Ocean from $40^{\circ} \mathrm{E}$ to $60^{\circ} \mathrm{E}$, of values of about $3 \times 10^{-5} \mathrm{~m} \mathrm{~s}^{-2}$ at $925 \mathrm{hPa}$. There is a secondary peak in the eastern Indian Ocean from $80^{\circ}$ to $90^{\circ} \mathrm{E}$, with a magnitude that is about $20 \%$ of the western major maximum. By contrast, the major peak of the semiannual zonal wind cycle is located from $50^{\circ}$ to $80^{\circ} \mathrm{E}$ (Fig. 3). The difference in zonal structure between momentum advection and zonal wind (Figs. 5a,c) is due to the pressure gradient adjustment as is discussed in the next section.

\section{Dynamical mechanisms}

\section{a. Linearized model}

Section 3 suggests that momentum advection can play a key role in the semiannual cycle in zonal wind. The budget analysis, however, does not address an important issue that the pressure term may be part of the dynamical adjustment to the momentum forcing. To address this issue, we use a linearized primitive model and study how pressure adjusts to the thermal and momentum forcing in the semiannual variability.

The model linearizes the dry atmospheric dynamical core and is forced with external thermal and momentum forcing. The model is on Mercator grid with a horizontal spacing of $2.5^{\circ}, 5$ levels vertical on sigma coordinates (Hirota et al. 2005). The model basic state is the annual mean of JRA25-JCDAS reanalysis from 1979 to 2008. Thermal forcing is derived as a residual term of the thermodynamic equation from the daily reanalysis datasets. Momentum forcing is derived as the horizontal momentum advection term of the momentum equation from monthly mean values [the rhs of Eq. (5)].

An $e$-folding time scale for Newtonian and Rayleigh damping is about 30 days in the free troposphere, and about 1 day at the lowest level $(\sigma=0.95)$. The high surface dissipation enables long-term integrations without developing baroclinic unstable waves due to a strong

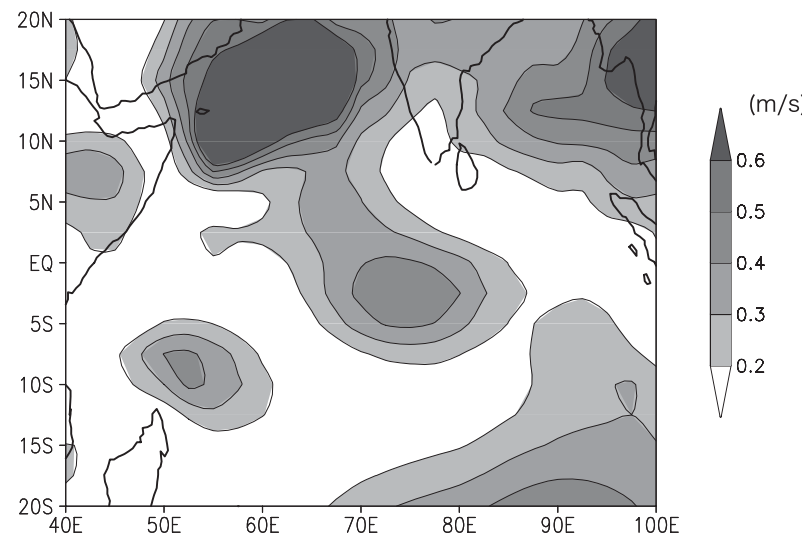

FIG. 7. Horizontal distribution of the standard deviation of the simulated zonal wind $\left(\mathrm{m} \mathrm{s}^{-1}\right)$ response to semiannual forcing (heating plus momentum advection) at $\sigma=0.95$

temperature gradient on the ground (Watanabe 2005; Watanabe and Kimoto 2000). In this model, surface stress is formulated as follows (Chiang et al. 2001; Nigam 1997)

$$
\left.K_{V} \frac{\partial u}{\partial \sigma}\right|_{\sigma=1}=\frac{p_{s} g}{R^{2} T^{2}} \frac{C_{D}|U|}{1-\sigma_{s}}\left(u_{s}-u\right),
$$

where $R$ is the ideal gas constant, $T$ is the temperature of the basic state, $p_{s}$ is the mean sea level pressure, $g$ is the gravity, $C_{D}$ is the surface drag coefficient, $U$ is the mean surface wind speed, $\sigma_{s}$ is the lowest vertical level of the model, and $u_{s}$ is the relative ground speed. The surface drag $\left(C_{D}\right)$ on land is set 10 times larger than over ocean. Under the monthly mean momentum and thermal forcing, a quasi-steady solution is obtained for each month from January to December by numerical integration for 20 days.

Figure 7 shows the horizontal distribution of the semiannual harmonic of zonal wind at the lowest model level. Compared to observations shown in Fig. 2b, the region of high semiannual signals in the central equatorial Indian Ocean is displaced slightly eastward and southward to about $75^{\circ} \mathrm{E}, 3^{\circ} \mathrm{S}$. The magnitude is weak. These biases may be due to large surface drag in the linear model. Nevertheless, the three maxima in the southwestern Indian Ocean $\left(\sim 55^{\circ} \mathrm{E}, 10^{\circ} \mathrm{S}\right)$, in the Arabian Sea $\left(60^{\circ} \mathrm{E}, 15^{\circ} \mathrm{N}\right)$ and especially near the equator $\left(75^{\circ} \mathrm{E}, 3^{\circ} \mathrm{S}\right)$ are well captured. The semiannual cycle in the western equatorial basin intensifies if the surface drag is reduced over land, indicating the importance of surface processes (not shown). In an experiment that removes the surface drag in Eq. (6) completely, the simulated response extends westward with the amplitude maximum displaced to around $60^{\circ} \mathrm{E}, 5^{\circ} \mathrm{N}$ (not shown).

To investigate whether the momentum advection is crucial to the semiannual cycle in the Indian Ocean, Fig. 8 
(a)

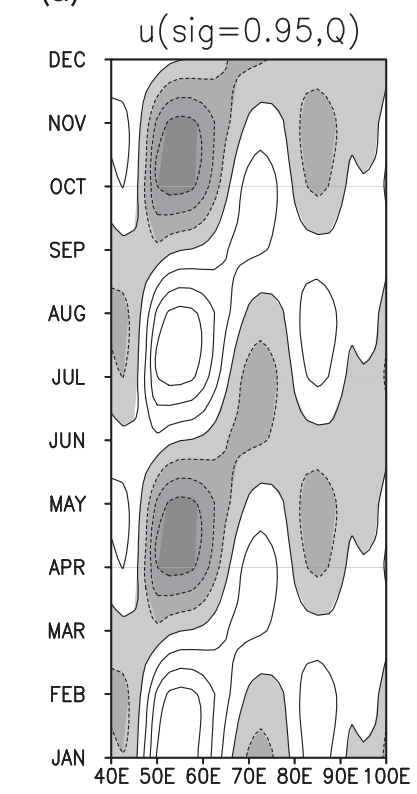

(b)

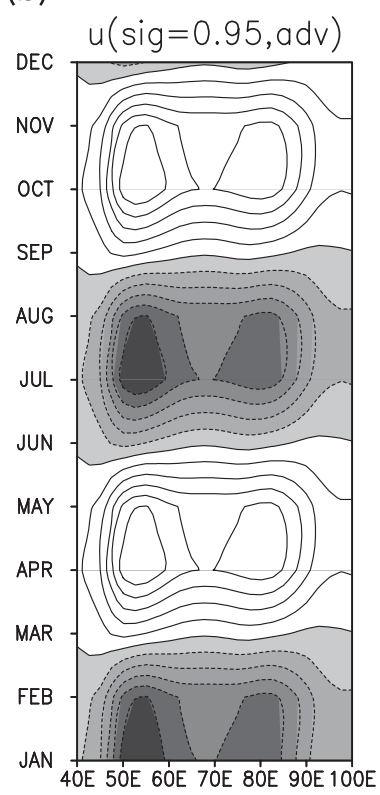

(c)

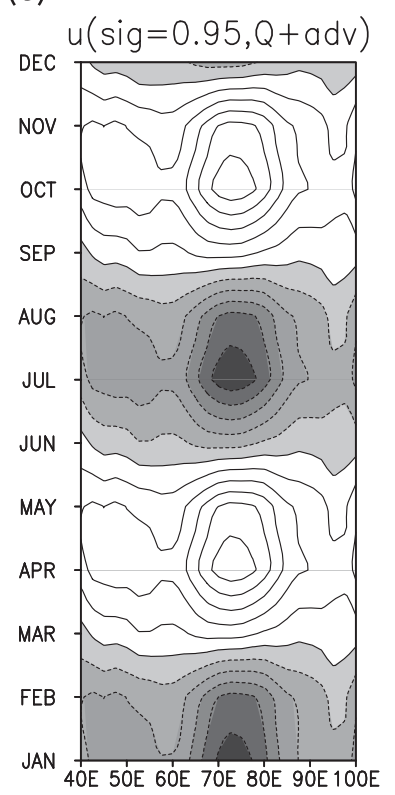

(d)

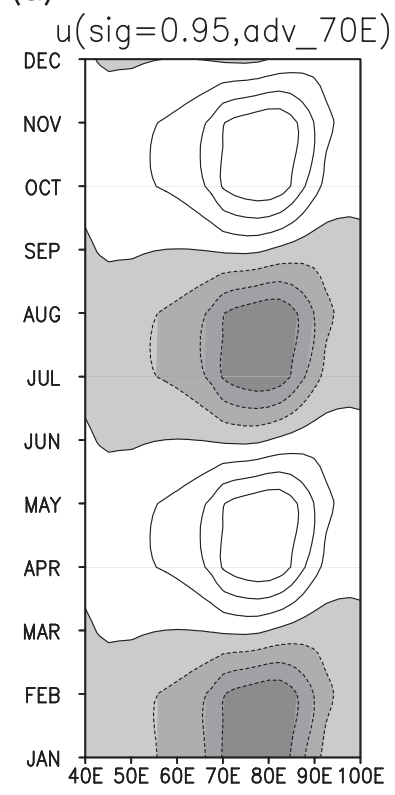

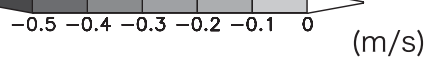

(m/s)

FIG. 8. Longitude-time sections of the simulated zonal wind $\left(\mathrm{m} \mathrm{s}^{-1}\right)$ on the equator in response to (a) heating only, (b) momentum advection only, and (c) heating plus momentum advection. (d) As in (b), but for the momentum advection imposed only east of $70^{\circ}$ E. Negative values are shaded.

compares the zonal wind response on the equator to heating only, to momentum advection only and to full forcing. It is apparent that the momentum forcing plays a dominant role especially in the western and central basins (Fig. 8b). The semiannual wind response to the diabatic heating is large only in the western basin (Fig. 8a), opposite in direction to the response to the full forcing (Fig. 8c). This thermal response reduces contribution by momentum advection in the west. In the central basin $\left(60^{\circ}-90^{\circ} \mathrm{E}\right)$, the heating effect is weak and the large semiannual variability is generated by the momentum forcing.

The momentum advection is strongest in the western basin because of the strong Somali jet. We investigate the relative importance of momentum advection between the western and eastern basin. To clarify this, the response to the momentum forcing imposed only east of $70^{\circ} \mathrm{E}$ is also examined (Fig. 8d). Comparison of Figs. 8c and $8 \mathrm{~d}$ shows that the momentum source east of $70^{\circ} \mathrm{E}$ explains about $80 \%$ of the total response in the central basin. This is counterintuitive given much larger momentum advection in the western than eastern basin. One possibility is that the African orography weakens the wind response to the momentum advection by the Somali jet, say by wave reflection.

Figure 9 shows the horizontal distribution of surface pressure simulated by the linear model for July. The response to heating generates high surface pressure in the western Indian Ocean and the resultant pressure gradient on the equator drives westerly winds (Fig. 9a). The response to the momentum forcing also makes the westerly acceleration by pressure gradient (Fig. 9b). Thus in the western basin, the pressure adjusts to both the heating and momentum advection to produce westerly winds consistent with the momentum budget in Fig. 5.

The above results suggest the following: the crossequatorial monsoon circulation generates easterly momentum advection in the western basin from $40^{\circ}$ to $60^{\circ} \mathrm{E}$ and in the eastern basin from $80^{\circ}$ to $90^{\circ} \mathrm{E}$ (Fig. 10a). In July, diabatic cooling is significant in the western Indian Ocean because of the surface cooling associated with the upwelling induced by the Somali jet (Fig. 10b). Surface pressure response to diabatic cooling induces westerlies, opposing the easterly momentum advection in the western basin (Fig. 10c).

\section{b. Equatorial wave adjustments}

Despite large momentum advection, why is zonal wind response weak in the western basin? Pressure gradient around $40^{\circ}-60^{\circ} \mathrm{E}$ is an important term in the momentum budget (Fig. 5a). Figure 9b shows that pressure gradient is part of dynamical adjustment to and opposes to the momentum advection. This subsection examines the dynamical adjustment. 
(a)

$$
\text { hgt }(\operatorname{sig}=0.95, \text { forcing }=Q, J u l)
$$
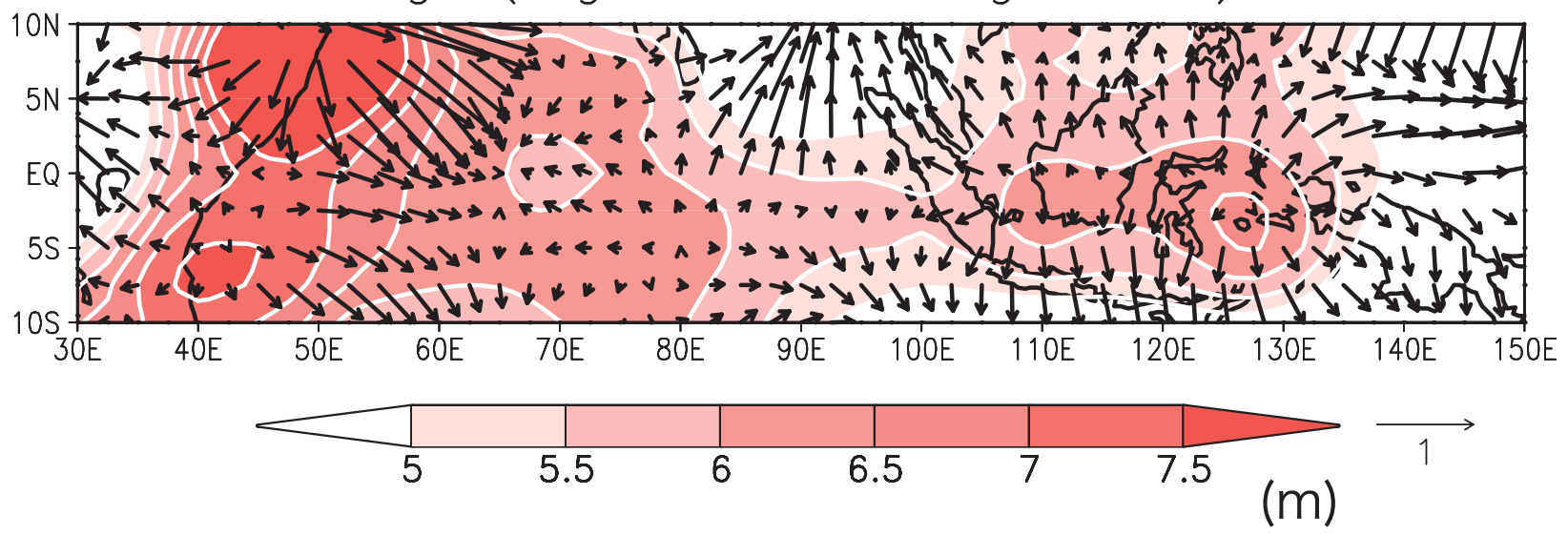

(b)

$$
\text { hgt }(\text { sig }=0.95 \text {, forcing }=a d v, J u l)
$$

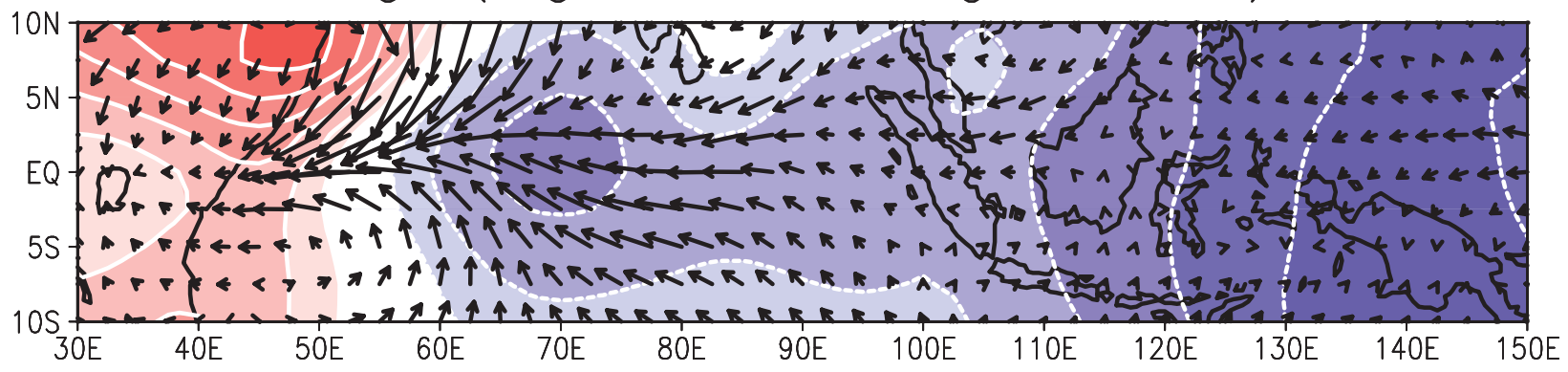

(c)

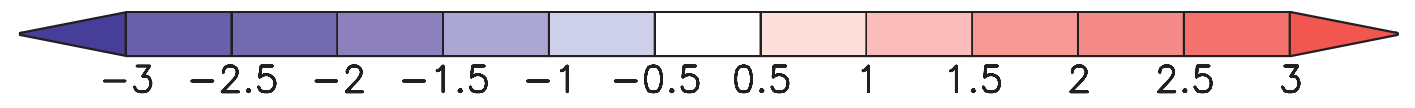

$$
\text { higt ( sig }=0.95 \text {, forcing }=Q+a d v, J u l)
$$
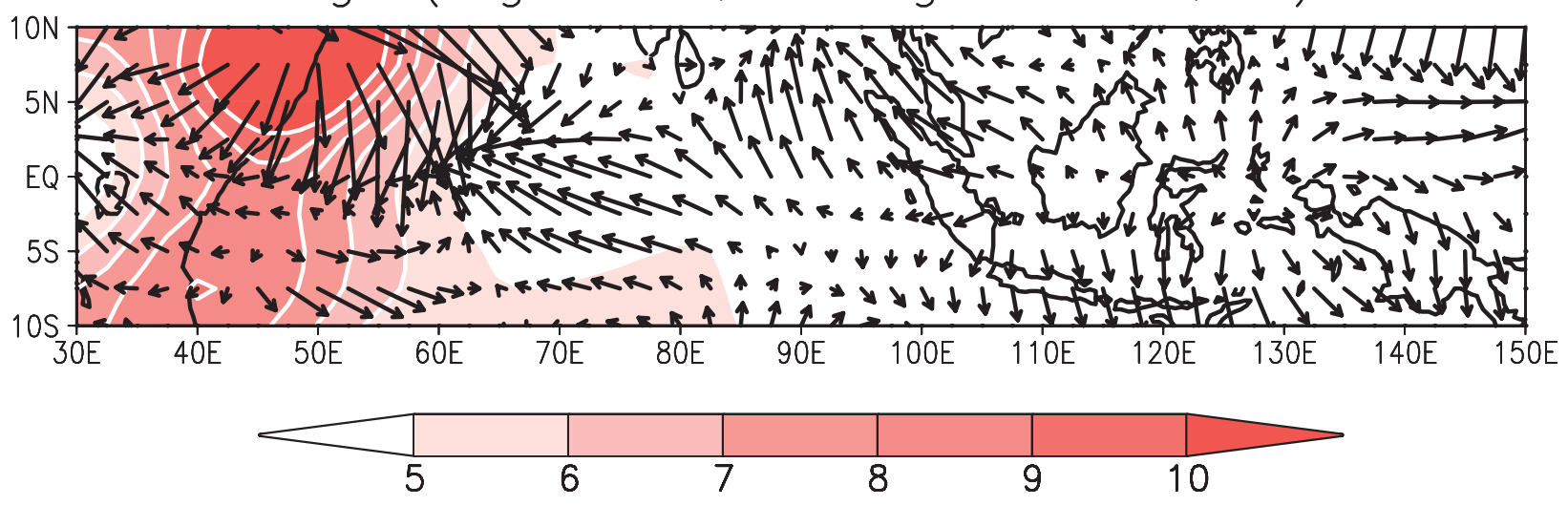

FIG. 9. July geopotential height anomalies $(\mathrm{m})$ and wind vectors $\left(\mathrm{m} \mathrm{s}^{-1}\right)$ simulated by the linearized model in response to (a) heating only, (b) momentum advection only, and (c) their sum at $\sigma=0.95$. 

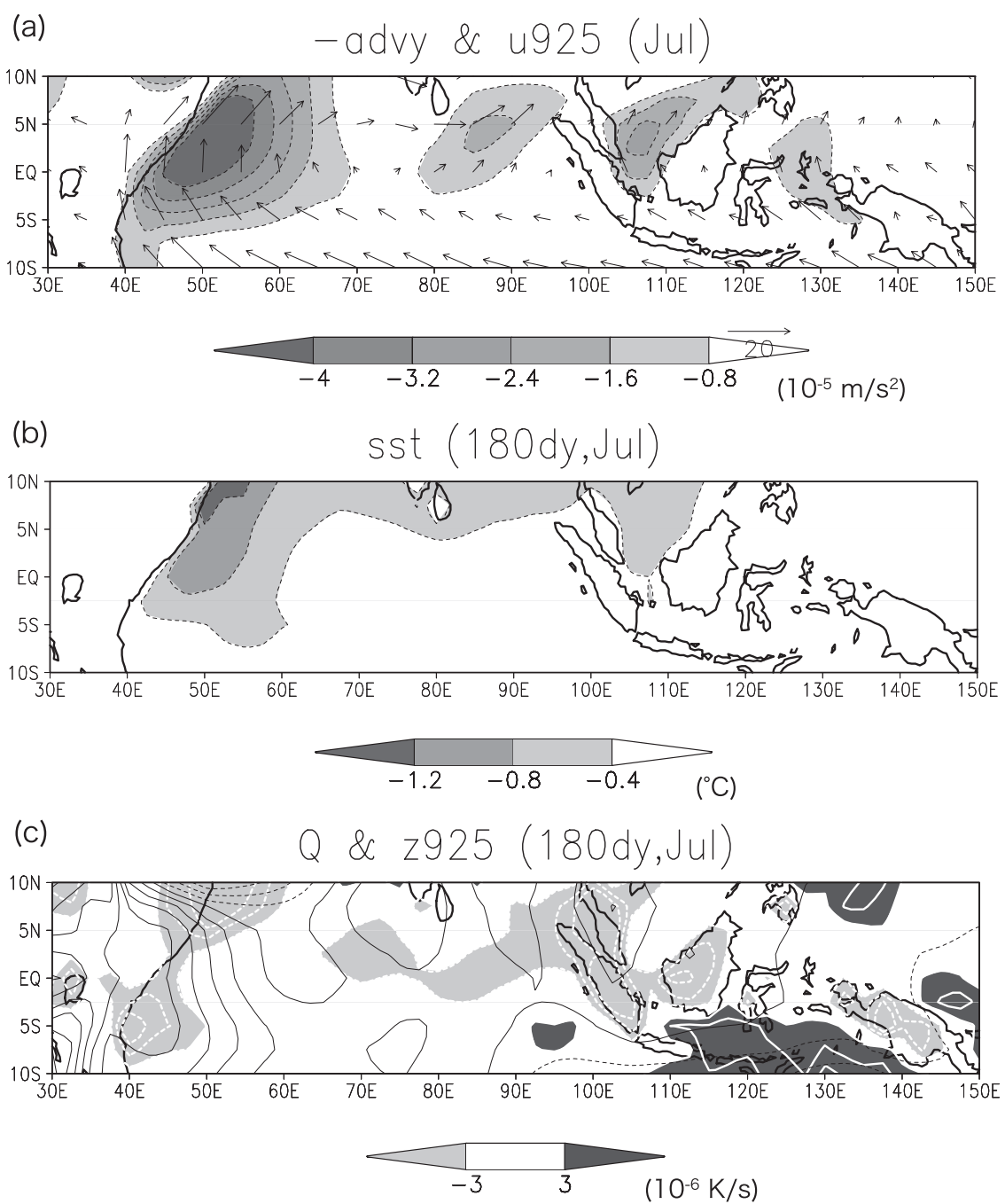

FIG. 10. July distributions of (a) wind (vector: $\mathrm{m} \mathrm{s}^{-1}$ ) and the semiannual component of momentum advection (shaded) at $925 \mathrm{hPa}$, (b) semiannual SST anomalies $\left({ }^{\circ} \mathrm{C}\right.$ ), and (c) semiannual component of the 925 -hPa geopotential height (contour) and vertical integrated diabatic heating (shaded). The shading and contour intervals are $0.8 \times 10^{-5} \mathrm{~m} \mathrm{~s}^{-2}$ [momentum advection in (a)], $1 \mathrm{~m}$ [geopotential height in (c)], and $3 \times 10^{-6} \mathrm{~K} \mathrm{~s}^{-1}$ [diabatic heating in (c)].

Orographic effects by the African Rift-Valley Mountains and African highlands may generate a counter effect on the momentum advection. This problem raises a question whether wave reflection at the western boundary can affect the formation of zonal wind on the equator. Furthermore, it is valuable to interpret the result in previous sections in a simple dynamical framework for a clear understanding.

Specifically, we investigate the role of equatorial waves in response to idealized thermal and momentum forcing, wave reflection at the lateral boundary, and its dependence on friction through the analytic solution of the equatorial wave dynamics within the PBL. We adopted the boundary layer model (Lindzen and Nigam 1987; Neelin 1989; Sarachik and Cane 2010). The PBL height is set at $1000 \mathrm{~m}$, temperature difference in the PBL top at $2 \mathrm{~K}$, and Rayleigh damping and Newtonian cooling coefficients at $1 \times 10^{-5} \mathrm{~s}^{-1}$. A solid boundary is placed at $x=$ 0 to mimic African mountains that are about $2 \mathrm{~km}$ high.

At first, we impose an easterly momentum forcing with a maximum of $0.5 \times 10^{-4} \mathrm{~m} \mathrm{~s}^{-2}$ in the open ocean $(2 \leq x \leq 4)$ centered on the equator to mimic the central basin forcing during boreal winter and summer. Here, distance $x$ is nondimensionalized by the Rossby radius of deformation, Ro $=932.8 \mathrm{~km}$. The lateral boundary in the western boundary for wave reflection is included. Figure 11a shows the forced Kelvin and Rossby waves, Kelvin wave reflected from the western boundary, and the total solution. The easterly momentum forcing excites a Kelvin wave of negative pressure and easterly 
(a)
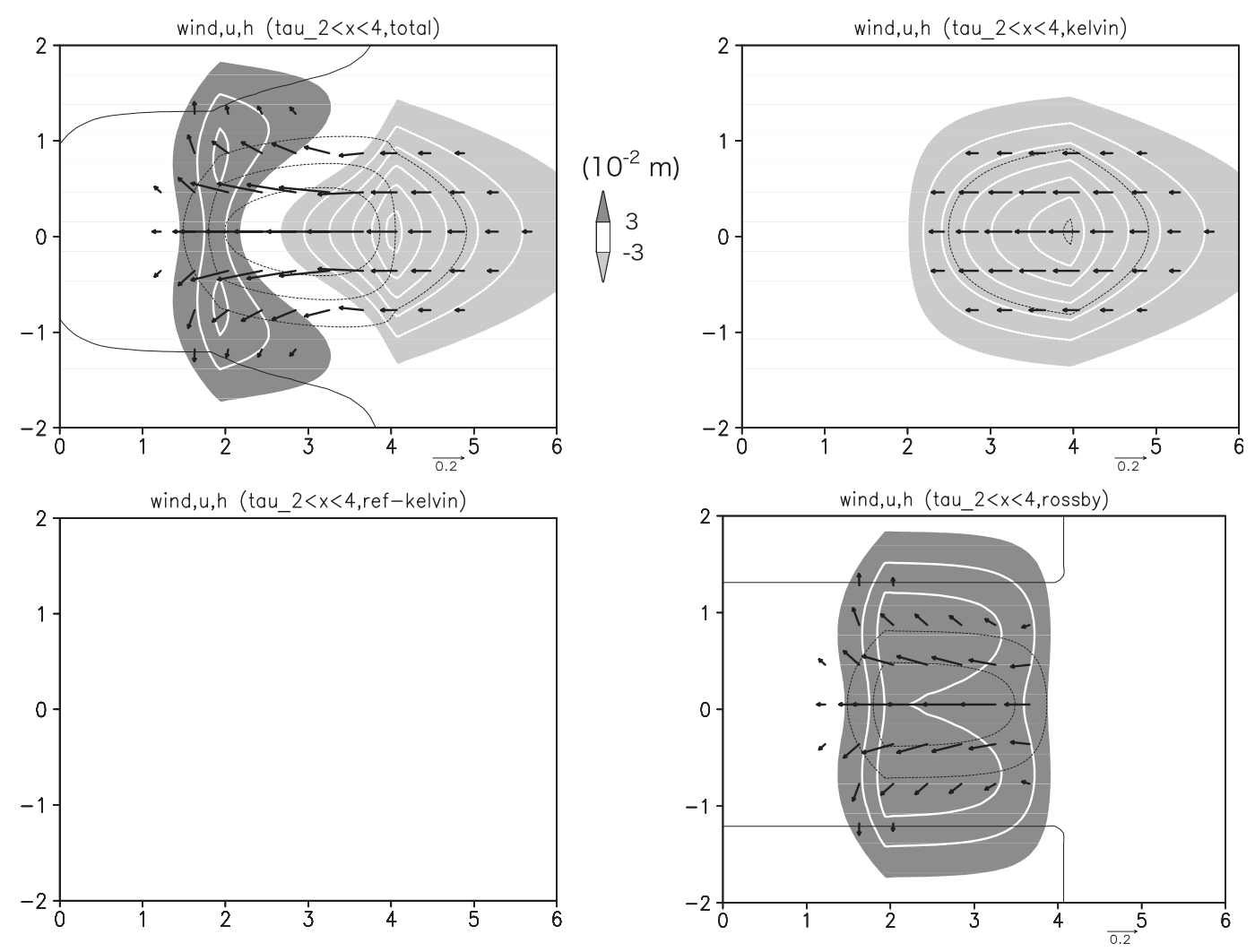

FIG. 11. (top left) Total, (top right) Kelvin, (bottom left) reflected Kelvin, and (bottom right) Rossby responses to (a) the easterly momentum forcing $\left(0.5 \times 10^{-4} \mathrm{~m} \mathrm{~s}^{-2}\right)$ in $2 \leq x \leq 4$; (b) the easterly momentum forcing $(2.5 \times$ $\left.10^{-4} \mathrm{~m} \mathrm{~s}^{-2}\right)$ in $0 \leq x \leq 2$; and (c) both the easterly momentum forcing $\left(2.5 \times 10^{-4} \mathrm{~m} \mathrm{~s}^{-2}\right)$ in $0 \leq x \leq 2$ and the negative thermal forcing (cold SST anomaly of $2^{\circ} \mathrm{C}$ ) in $0 \leq x \leq 1$. Solutions are derived from the Lindzen and Nigam (1987) model. Contour (shade) indicates the zonal wind (perturbation height in $10^{-2} \mathrm{~m}$ ). The contour intervals are $0.03 \mathrm{~m}$ [perturbation height in (a),(b)], $0.09 \mathrm{~m}$ [perturbation height in (c)], and $0.1 \mathrm{~m} \mathrm{~s}^{-1}$ (zonal wind). The wind vector is drawn only in case of the wind speed $>0.04 \mathrm{~m} \mathrm{~s}^{-1}$.

anomalies, which extends to the east and decays in the unforced region. Accompanied by positive pressure and easterly anomalies, the Rossby wave response is strongly damped and restricted to the forcing region. The reflection of Rossby waves on the western boundary is very weak. The total solution features a dipole pressure response, with negative (positive) in the east (west). In between, there are easterly winds that peak on the equator (Fig. 11b).

Next, we examine the western boundary effect by placing the momentum forcing in the western Indian Ocean $(0 \leq x \leq 2)$, with a maximum of $2.5 \times 10^{-4} \mathrm{~m} \mathrm{~s}^{-2}$ centered on the equator. Note that we have increased the magnitude of the momentum forcing by a factor of 5 to be consistent with observations in the western basin. Figure 11b shows the reflected Kelvin response from the western boundary is larger than in the case of the open ocean forcing, but it is not large enough to cancel completely the strong Kelvin and Rossby responses. Easterly winds peak at $x=1.25$. Thus the western boundary reflection, a pressure adjustment, does not seem to explain by itself the weak semiannual cycle in zonal wind in observations. We note, however, the magnitude and eastward extension of the reflected Kelvin wave are sensitive to surface friction, increasing with decreased drag. This sensitivity is hard to quantify given the large difference in drag between land and ocean.

Another possible effect to reduce the excessive easterly response in the west is the semiannual diabatic heating off Somalia. As suggested by the analysis results in Fig. 10, we investigate the heating effect in the western basin by imposing a cool SST anomaly $\left(2^{\circ} \mathrm{C}\right)$ near the western boundary $(0 \leq x \leq 1)$. Figures $11 \mathrm{a}-\mathrm{c}$ show that the easterly response significantly weakens east of the cooling region. This response is mostly made of Rossby and Kelvin waves similar to the Matsuno-Gill pattern (Matsuno 1966; Gill 1980), but the wave reflection from the western boundary also has a significant contribution to enhance the thermally induced westerly response. 
(b)
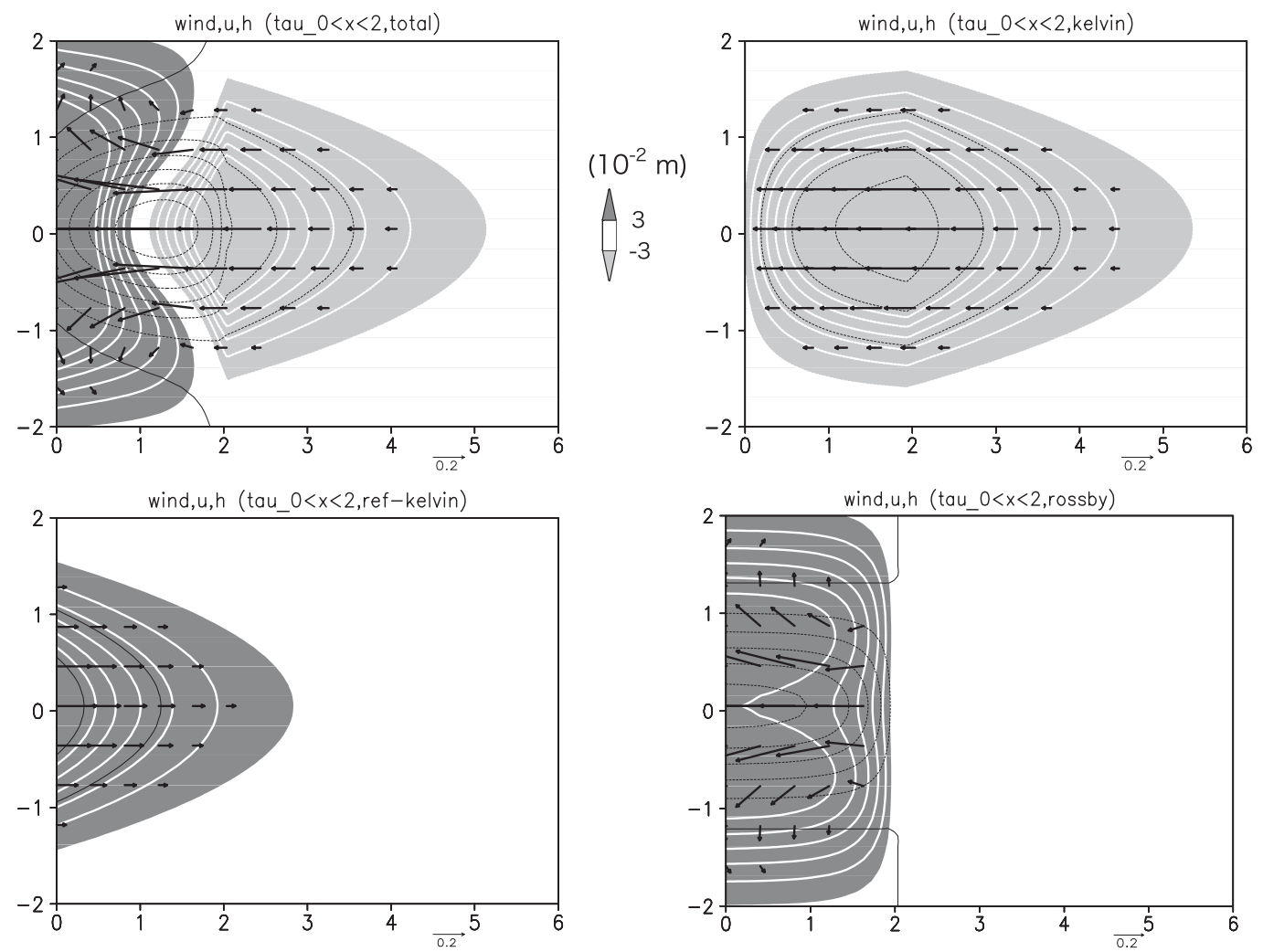

(c)
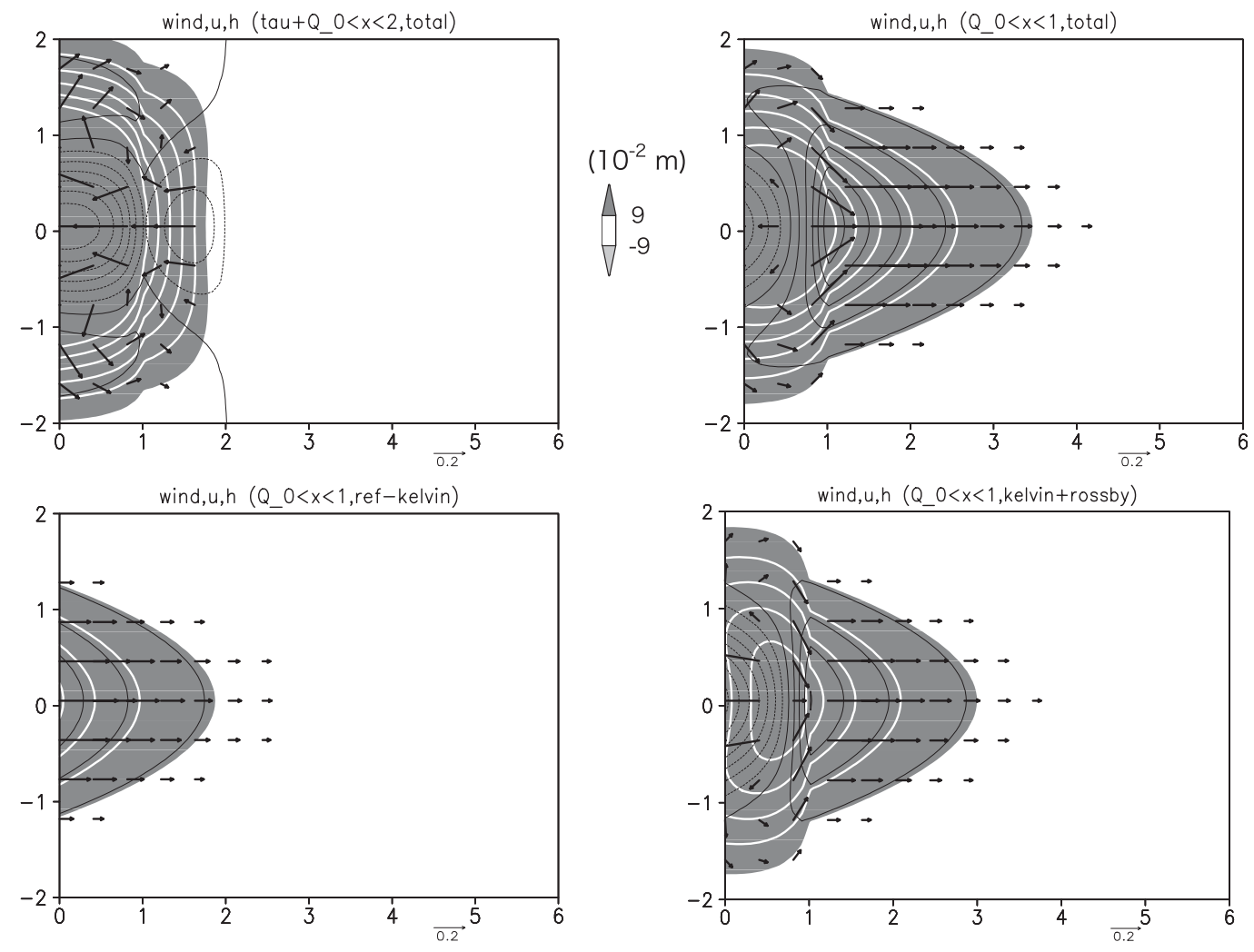

FIG. 11. (Continued) 


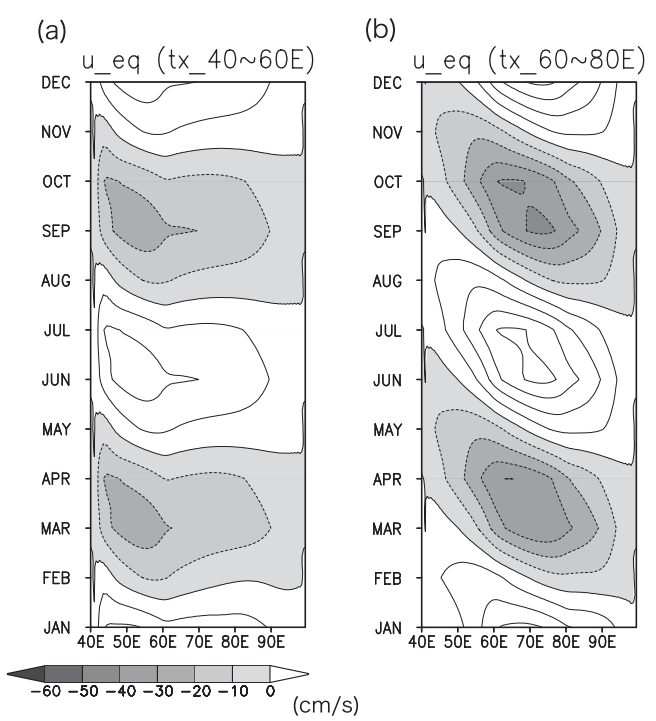

(c)

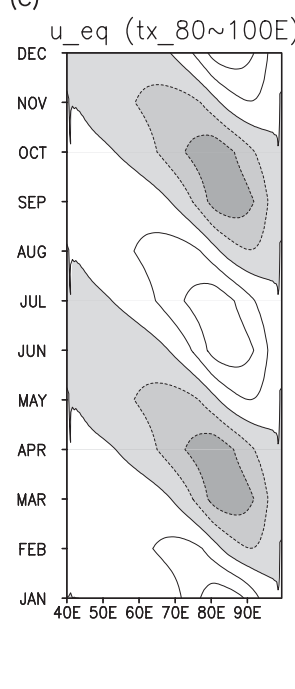

(d)

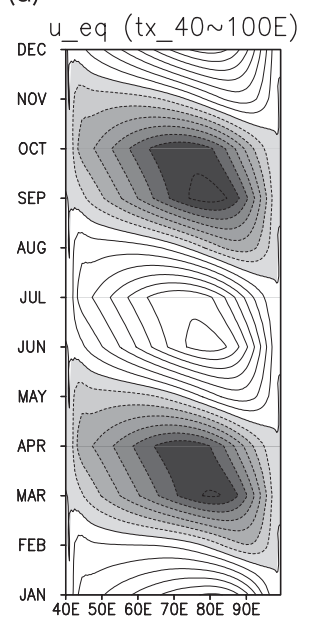

FIG. 12. Longitude-time sections of the simulated zonal current $\left(\mathrm{cm} \mathrm{s}^{-1}\right)$ on the equator in response to the semiannual wind forcing (a) in the west $\left(40^{\circ}-60^{\circ} \mathrm{E}\right)$, (b) central $\left(60^{\circ}-80^{\circ} \mathrm{E}\right)$, (c) east $\left(80^{\circ}-100^{\circ} \mathrm{E}\right)$, and (d) entire $\left(40^{\circ}-100^{\circ} \mathrm{E}\right)$ basin. Negative values are shaded.

West of the cooling region $(x \leq 1)$, a strong easterly response still remains. In the real atmosphere, the easterly response near Africa could be weakened by large surface friction over land.

\section{Oceanic response to the semiannual wind}

The oceanic response to the semiannual wind cycle in the tropical Indian Ocean has been investigated in several studies (Yamagata et al. 1996; Han et al. 1999). In particular, Han et al. (1999) suggested that with the semiannual forcing, the basin size satisfies the condition for resonance in the equatorial waveguide between Rossby and Kelvin waves (Cane 1980). Section 4 shows the momentum forcing, the wave reflection by African mountains, and SST forcing off Somalia are all important to place the maximum of the semiannual cycle in zonal wind in the central basin. In this section, we examine the sensitivity of the oceanic response to the forcing longitude and the role of reflected waves. A linear, continuously stratified ocean model is used in this study (e.g., McCreary 1984; Miyama et al. 2006). In this model, a solution is decomposed into 20 vertical modes for the density profile of the World Ocean Atlas 1998 (WOA98) averaged $60^{\circ}-80^{\circ} \mathrm{E}$ on the equator. The shallow water equation is solved for each vertical mode. A vertical viscosity of $8.84 \times 10^{-4} \mathrm{~cm}^{2} \mathrm{~s}^{-1}$ is chosen in this study, equivalent to damping time scales of $1104,537,252.1$, and 131.6 days for the first, second, third, and fourth vertical mode.

Figure 12 shows the surface zonal current response to the semiannual wind forcing with different zonal structures: $40^{\circ}-60^{\circ} \mathrm{E}$ (western basin; Fig. $12 \mathrm{a}$ ), $60^{\circ}-80^{\circ} \mathrm{E}$ (central; Fig. $12 \mathrm{~b}$ ), $80^{\circ}-100^{\circ} \mathrm{E}$ (eastern; Fig. 12c), and $40^{\circ}-100^{\circ} \mathrm{E}$ (whole basin; Fig. 12d). The zonal wind forcing is uniform in the zonal patch and follows a Gaussian function of $5^{\circ}$ width in the meridional direction. In spite of the same amplitude and width of the forcing patch, the response to the central forcing is about $40 \mathrm{~cm} \mathrm{~s}^{-1}$, which is significantly stronger than in either the western and eastern basin cases (about $20 \mathrm{~cm} \mathrm{~s}^{-1}$ ). The response to the basinwide forcing (Fig. 12d) is strongest in the central and eastern basin $\left(60^{\circ}-90^{\circ} \mathrm{E}\right)$ because slow westward propagation of Rossby wave generated in the eastern basin (Fig. 12c) cancels especially in western case (Fig. 12a) due to the out-of-phase relationship. Lower vertical modes contribute the most because the responses of higher modes cannot travel far with shorter damping time scales.

The semiannual cycle in the upper ocean has a potential impact on the seasonal phase locking of interannual variability. Figure 13 shows the semiannual component of the $20^{\circ} \mathrm{C}$ isotherm and the standard deviation of interannual anomaly in SST. The semiannual cycle of the thermocline depth takes a minimum in December and June (February and August) in the western (eastern) basin. The standard deviation of the interannual SST variability also has a significant semiannual cycle over the western equatorial Indian Ocean (Xie et al. 2002), locked onto the semiannual shoaling of the thermocline. Interannual variability in the east is locked onto the September-November season, preceded by a local thermocline shoaling. It is the signature of the IOD mode. 


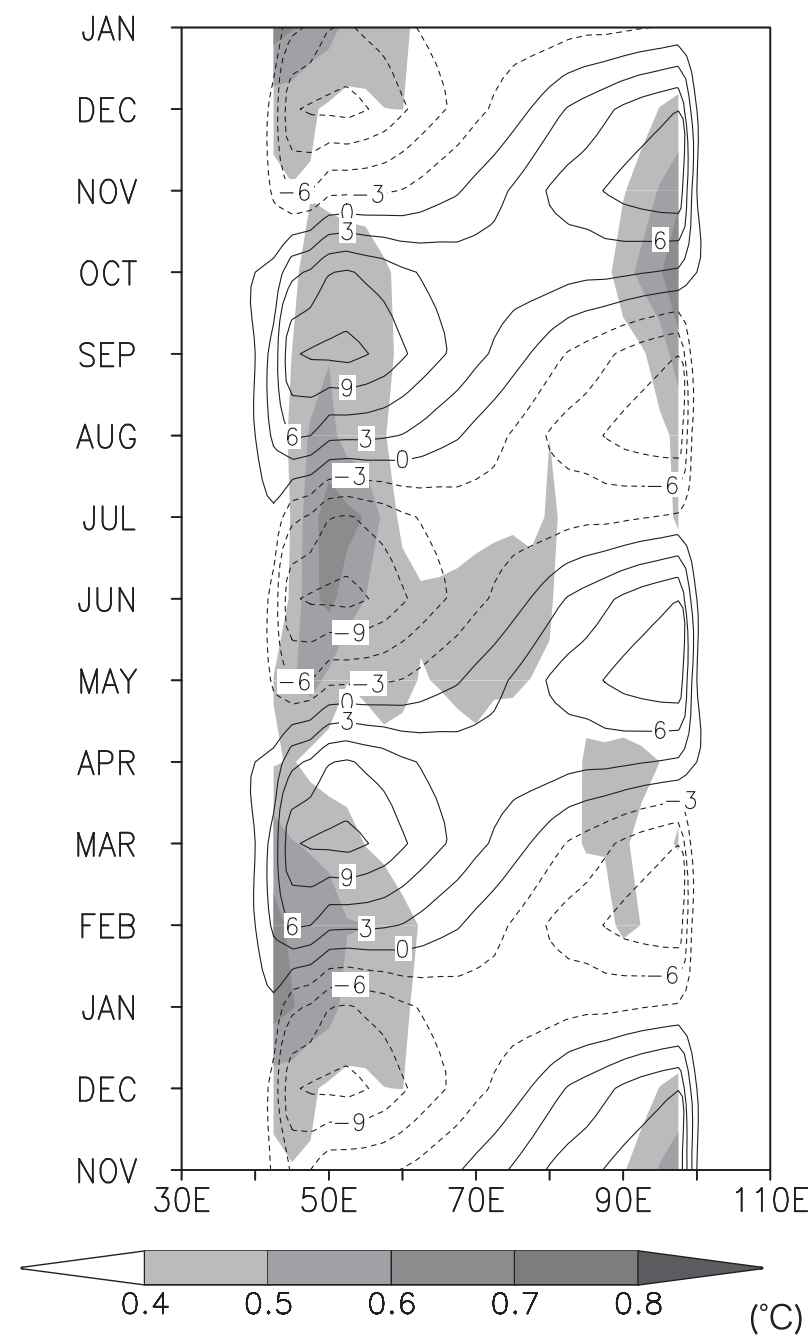

FIG. 13. Longitude-time sections of the semiannual component of the $20^{\circ} \mathrm{C}$ isotherm derived from version 1.2 of the Simple Ocean Data Assimilation reanalysis product (SODA-1.2) (contour) and the standard deviation of the interannual component of monthly SST anomaly $\left({ }^{\circ} \mathrm{C}\right)$ derived from optimally interpolated SST (OISST) (shaded) on the equator.

\section{Summary and discussion}

We have investigated the mechanisms for the semiannual zonal wind cycle in the equatorial Indian Ocean. By analyzing results from an atmospheric reanalysis and a linearized primitive model, we have showed that momentum advection due to the cross-equatorial monsoon circulation is important. In observations, the semiannual cycle in zonal wind is most pronounced on the equator and confined below $800 \mathrm{hPa}$. A momentum budget analysis shows that the momentum advection is dominant in the central equatorial Indian Ocean while it is opposed by the zonal pressure gradient in the western basin. Linear models shed light on dynamical adjustments to cross-equatorial momentum advection. Pressure perturbations in the Matsuno-Gill pattern are induced by imposing momentum forcing. In particular, pressure anomalies of the reflected Kelvin wave by African mountains weaken the zonal wind response to momentum advection forcing in the western basin. The semiannual cycle in zonal wind is further reduced by SST cooling off Africa in response to the Somali wind jet during boreal summerwinter. As a result of the wave reflection and the local SST cooling on the African coast, the semiannual zonalwind variability reaches a maximum in the central equatorial Indian Ocean despite much stronger momentum advection in the west.

Our results suggest the following conceptual model for the semiannual cycle in equatorial zonal wind (Fig. 14a). During boreal summer (or winter), a cross-equatorial monsoon circulation is set up over the Indian Ocean. In the PBL, the cross-equatorial flow advects easterly momentum from the upstream, inducing easterly winds on the equator where the Coriolis force vanishes and cannot balance the momentum advection. The easterly momentum advection is greatest off Africa but the semiannual cycle in zonal wind reaches a maximum in the central basin. Wave reflection by African mountains and SST cooling by coastal upwelling limit the zonal wind response in the west, enabling weaker open-ocean momentum advection to dominate in the central Indian Ocean. The ocean response, the Yoshida-Wyrtki jet in particular, is most pronounced if the semiannual wind forcing peaks in the central basin as in observations. As the cross-equatorial momentum advection is of leadingorder importance, the pronounced semiannual cycle in equatorial zonal wind and the oceanic Yoshida-Wyrtki jets should be considered as a response to the interhemispheric monsoon circulation (Fig. 14b).

The western Pacific is similar to the Indian Ocean in the cross-equatorial wind reversing its direction between winter and summer. Indeed, the zonal-momentum budget on the equator indicates that the cross-equatorial momentum advection is important for the semiannual wind cycle there (Fig. 4b). The eastern Pacific and Atlantic features a very different seasonal cycle on the equator from the Indo-western Pacific Oceans. In the former oceans, the ITCZ is permanently displaced north of the equator, and the cross-equatorial wind remains southerly year-round (Mitchell and Wallace 1992; Xie 2004). Instead of a semiannual cycle in zonal wind, the crossequatorial momentum advection by the seasonal-varying southerlies generates an annual cycle and intensifies the equatorial easterlies during boreal summer-fall as shown by Okumura and Xie (2004). The comparison between the Indo-western Pacific and eastern Pacific-Atlantic illustrates the importance of mean states, especially with 
(a)

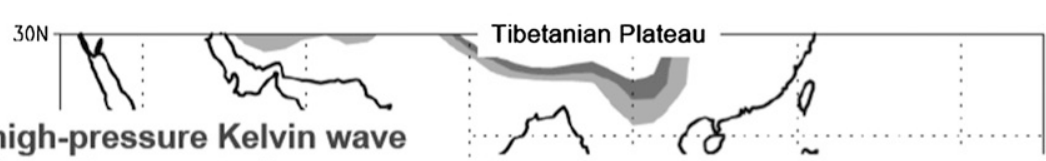

3. high-pressure Kelvin wave with surface westerlies

1. interhemispheric monsoon flow

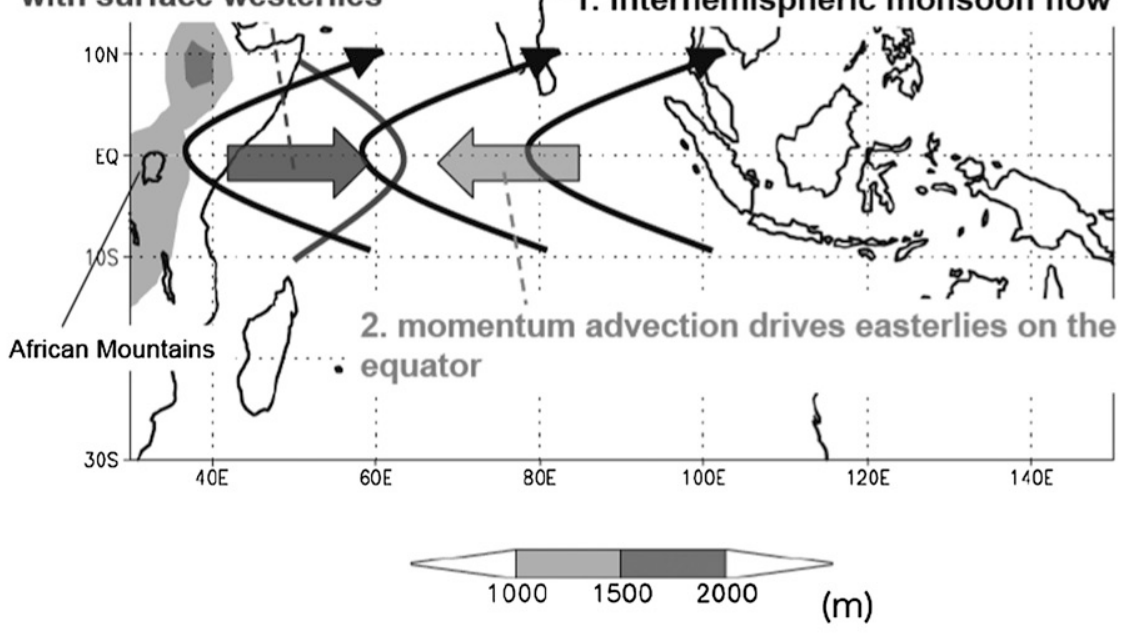

(b)

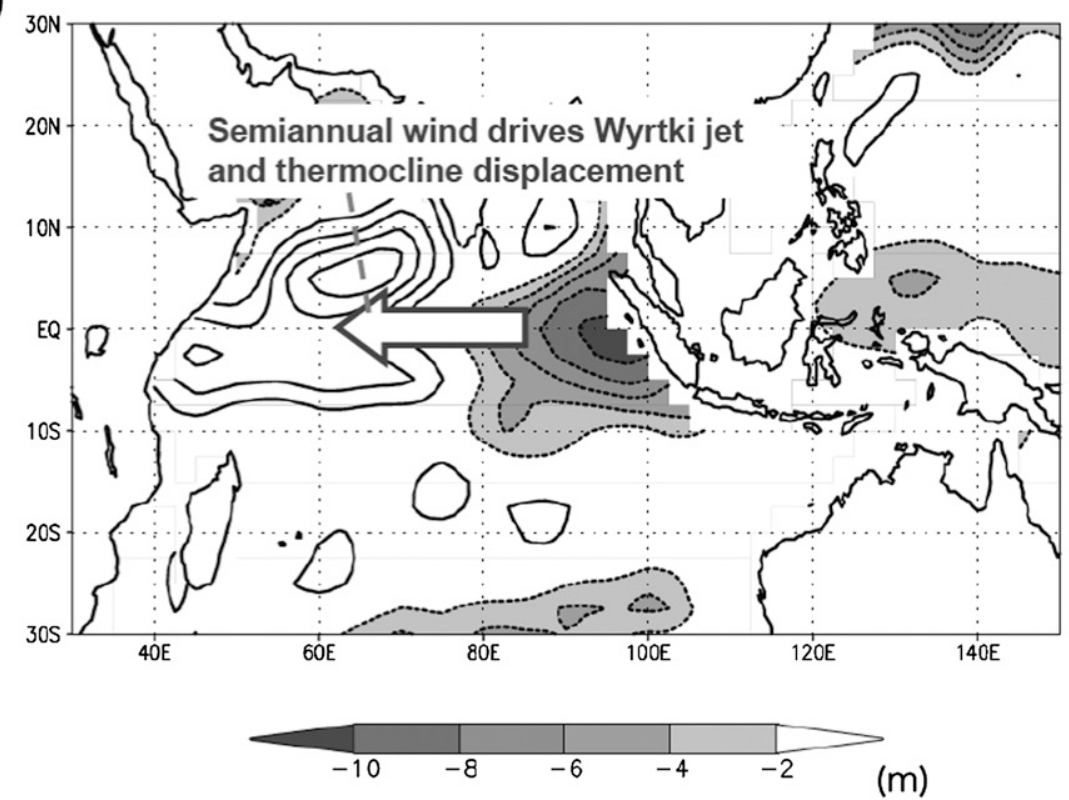

FIG. 14. (a) A schematic view of monsoon circulation, cross-equatorial momentum advection, and the easterly acceleration during the boreal summer. (b) A schematic view of the oceanic response to the semiannual wind cycle. Shading in (a) indicates land orography. Contour in (b) indicates the semiannual component of $20^{\circ} \mathrm{C}$ themocline depth (negative values shaded) in boreal summer based on SODA.

regard to the ITCZ and the cross-equatorial wind, reaffirming the key role of the cross-equatorial monsoon circulation in the semiannual cycle of zonal wind over the equatorial Indian Ocean.

Acknowledgments. We wish to thank W. Han and J. McCreary for constructive discussions, and Naoki
Sato for providing the linearized atmospheric model. This research is supported by the U.S. National Science Foundation, and the Japan Agency for Marine-Earth Science and Technology (JAMSTEC) - International Pacific Research Center (IPRC) Initiative project (JII). This publication has been assigned IPRC Publication Number 813. 


\section{REFERENCES}

Behera, S. K., S. A. Rao, H. N. Saji, and T. Yamagata, 2003: Comments on "A cautionary note on the interpretation of EOFs." J. Climate, 16, 1087-1093.

_ J. J. Luo, S. Masson, S. A. Rao, H. Sakuma, and T. Yamagata, 2006: A CGCM study on the interaction between IOD and ENSO. J. Climate, 19, 1688-1705.

Cane, M. A., 1980: On the dynamics of equatorial currents, with application to the Indian Ocean. Deep-Sea Res., 27A, 525-544.

Chiang, J. C. H., S. E. Zebiak, and M. A. Cane, 2001: Relative roles of elevated heating and surface temperature gradients in driving anomalous surface winds over tropical oceans. J. Atmos. Sci., $\mathbf{5 8 ,}$ 1371-1394.

Clarke, A. J., and X. Liu, 1993: Observations and dynamics of semiannual and annual sea levels near the eastern equatorial Indian Ocean boundary. J. Phys. Oceanogr., 23, 386-399.

Fiorino, M., 2002: Analysis and forecasts of tropical cyclones in the ECMWF 40-year reanalysis (ERA-40). Preprints, 25th Conf. on Hurricanes and Tropical Meteorology, San Diego, CA, Amer. Meteor. Soc., 5D.2. [Available online at http://ams.confex. com/ams/25HURR/techprogram/paper_38743.htm.]

Gent, P. R., K. O'Neill, and M. A. Cane, 1983: A model of the semiannual oscillation in the equatorial Indian Ocean. J. Phys. Oceanogr., 13, 2148-2160.

Gill, A. E., 1980: Some simple solutions for heat-induced tropical circulation. Quart. J. Roy. Meteor. Soc., 106, 447-462.

Han, W., J. P. McCreary, D. L. T. Anderson, and A. J. Mariano, 1999: Dynamics of the eastern surface jets in the equatorial Indian Ocean. J. Phys. Oceanogr., 29, 2191-2209.

Hendon, H. H., and M. L. Salby, 1994: The life cycle of the MaddenJulian oscillation. J. Atmos. Sci., 51, 2225-2237.

Hirota, N., M. Takahashi, N. Sato, and M. Kimoto, 2005: Recent climate trends in the East Asia during the Baiu season of 19792003. SOLA, 1, 137-140, doi:10.2151/sola.2005-036.

Jensen, T. G., 1993: Equatorial variability and resonance in a winddriven Indian Ocean model. J. Geophys. Res., 98 (C12), 22 53322552.

Knox, R., 1976: On a long series of measurements of Indian Ocean equatorial currents near Addu Atoll. Deep-Sea Res., 23, 211-221.

Lindzen, R. S., and S. Nigam, 1987: On the role of sea surface temperature gradients in forcing low-level winds and convergence in the tropics. J. Atmos. Sci., 44, 2418-2436.

Luyten, J., and D. Roemmich, 1982: Equatorial currents at semiannual period in the Indian Ocean. J. Phys. Oceanogr., 12, 406-413.

Madden, R. A., 1986: Seasonal variations of the 40-50 day oscillation in the tropics. J. Atmos. Sci., 43, 3138-3158.

Matsuno, T., 1966: Quasi-geostrophic motions in the equatorial area. J. Meteor. Soc. Japan, 44, 25-43.

McCreary, J. P., 1984: Equatorial beams. J. Mar. Res., 42, 395-430.

McPhaden, M. J., 1982: Variability in the central equatorial Indian Ocean. Part 1: Ocean dynamics. J. Mar. Res., 40, 157-176.

Mitchell, T., and J. M. Wallace, 1992: The annual cycle in equatorial convection and sea surface temperature. J. Climate, 5, 1140-1156.

Miyama, T., J. P. McCreary, D. Sengupta, and R. Senan, 2006: Dynamics of biweekly oscillations in the equatorial Indian Ocean. J. Phys. Oceanogr., 36, 827-846.

Murtugudde, R., and A. J. Busalacchi, 1999: Interannual variability of the dynamics and thermodynamics of the tropical Indian Ocean. J. Climate, 12, 2300-2326.

Nagura, M., and M. J. McPhaden, 2008: The dynamics of zonal current variations in the central equatorial Indian Ocean Geophys. Res. Lett., 35, L23603, doi:10.1029/2008GL035961.
Neelin, J. D., 1989: On the interpretation of the Gill model. J. Atmos. Sci., 46, 2466-2468.

Nigam, S., 1997: The annual warm to cold phase transition in the eastern equatorial Pacific: Diagnosis of the role of stratus cloud-top cooling. J. Climate, 10, 2447-2467.

Okumura, Y., and S.-P. Xie, 2004: Interaction of the Atlantic equatorial cold tongue and African monsoon. J. Climate, 17, 3588-3601.

Onogi, K., and Coauthors, 2007: The JRA-25 Reanalysis. J. Meteor. Soc. Japan, 85, 369-432.

Qu, T., Y. Du, J. P. McCreary Jr., G. Meyers, and T. Yamagata, 2008: Buffering effect and its related ocean dynamics in the Indonesian Throughflow region. J. Phys. Oceanogr., 38, 503-516.

Reppin, J., F. A. Schott, and J. Fischer, 1999: Equatorial currents and transports in the upper central Indian Ocean: Annual cycle and interannual variability. J. Geophys. Res., 104, 15 49515514.

Saji, N. H., and T. Yamagata, 2003: Interference of teleconnection patterns generated from the tropical Indian and Pacific Oceans. Climate Res., 25, 151-169.

_ B. B. Goswami, P. N. Vinayachandran, and T. Yamagata, 1999: A dipole mode in the tropical Indian Ocean. Nature, 401, 360-363.

— S.-P. Xie, and T. Yamagata, 2006: Tropical Indian Ocean variability in the IPCC twentieth-century climate simulations. J. Climate, 19, 4397-4417.

Sarachik, E. S., and M.A. Cane, 2010: The El Niño-Southern Oscillation Phenomenon. Cambridge University Press, 384 pp.

Schott, F. A., and J. P. McCreary, 2001: The monsoon circulation of the Indian Ocean. Prog. Oceanogr., 51, Pergamon, 1-123.

_ S.-P. Xie, and J. P. McCreary, 2009: Indian Ocean circulation and climate variability. Rev. Geophys., 47, RG1002, doi:10.1029/ 2007RG000245.

Watanabe, M., cited 2005: Linear Baroclinic Model (LBM) package users' guide version 2.2. [Available online at http:// www.ccsr.u-tokyo.ac.jp/ hiro/sub/lbm.html.]

—, and M. Kimoto, 2000: Atmosphere-ocean thermal coupling in the North Atlantic: A positive feedback. Quart. J. Roy. Meteor. Soc., 126, 3343-3369.

Webster, P. J., A. Moore, J. Loschnigg, and M. Leban, 1999: Coupled ocean-atmosphere dynamics in the Indian Ocean during 1997-98. Nature, 40, 356-360.

Wyrtki, K., 1973: An equatorial jet in the Indian Ocean. Science, 181, 262-264.

Xie, S.-P., 2004: The shape of continents, air-sea interaction, and the rising branch of the Hadley circulation. The Hadley Circulation: Past, Present and Future, H. F. Diaz and R. S. Bradley, Eds., Kluwer Academic Publishers, 121-152.

- H. Annamalai, F. A. Schott, and J. P. McCreary, 2002: Structure and mechanisms of south Indian Ocean climate variability. J. Climate, 15, 864-878.

Yamagata, T., K. Mizuno, and Y. Masumoto, 1996: Seasonal variations in the equatorial Indian Ocean and their impact on the Lombok throughflow. J. Geophys. Res., 101 (C5), 12 465-12 473.

Yoshida, K., 1959: A theory of the Cromwell current and of the equatorial upwelling-An interpretation in a similarity to a coastal circulation. J. Oceanogr. Soc. Japan, 15, 159-170.

Yuan, D., and W. Han, 2006: Roles of equatorial waves and western boundary reflection in the seasonal circulation of the equatorial Indian Ocean. J. Phys. Oceanogr., 36, 930-944.

Zhang, C., 2005: Madden-Julian oscillation. Rev. Geophys., 43, RG2003, doi:10.1029/2004RG000158. 